\title{
Isabelle Charpentier, Christine Détrez, Abir Kréfa (dir.), Socialisations, identités et résistances des romancières du Maghreb. Avoir voix au chapitre
}

\section{Claudia Mansueto}

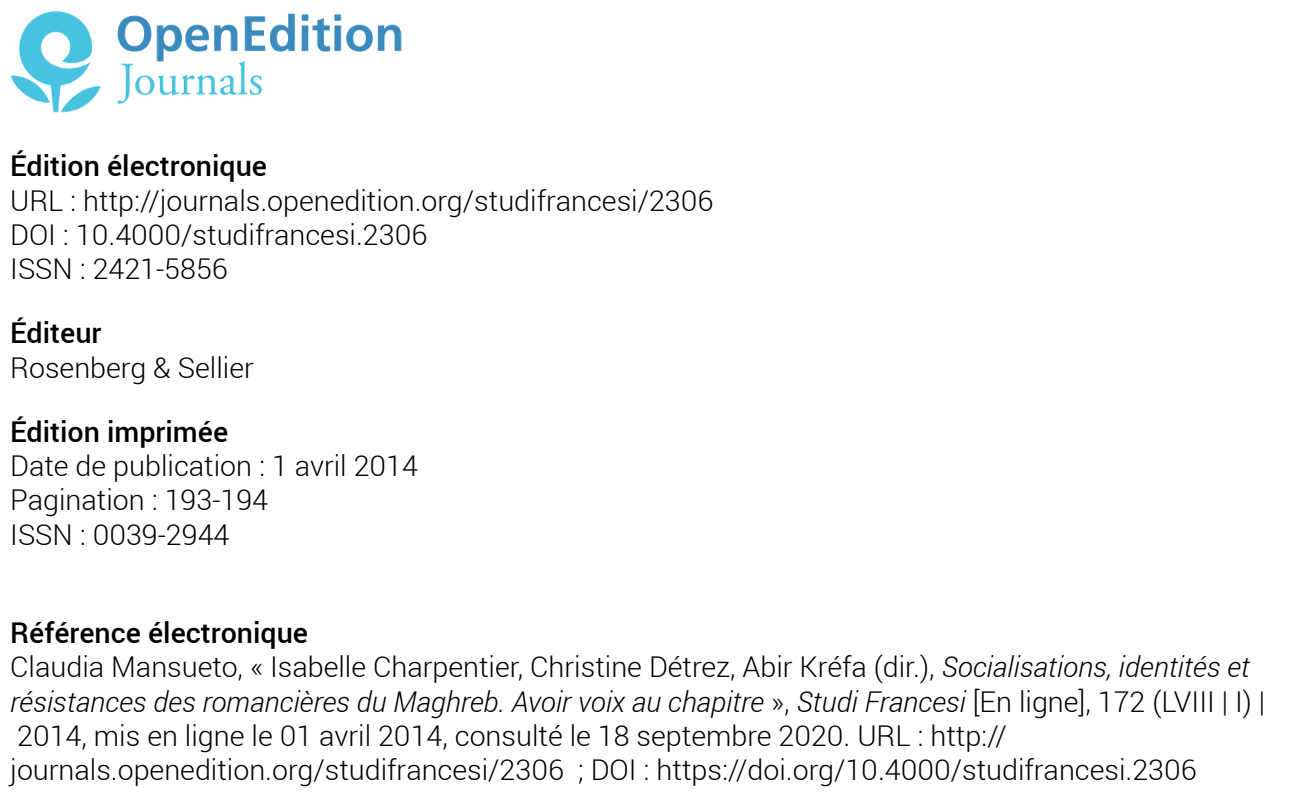

Ce document a été généré automatiquement le 18 septembre 2020.

\section{(1) $\odot \Theta \Theta$}

Studi Francesi è distribuita con Licenza Creative Commons Attribuzione - Non commerciale - Non opere derivate 4.0 Internazionale. 


\title{
Isabelle Charpentier, Christine Détrez, Abir Kréfa (dir.), Socialisations, identités et résistances des romancières du Maghreb. Avoir voix au chapitre
}

\author{
Claudia Mansueto
}

\section{RÉFÉRENCE}

ISABELLE CHARPENTIER, CHRISTINE DÉTREZ, ABIR KRÉFA (dir.), Socialisations, identités et résistances des romancières du Maghreb. Avoir voix au chapitre, Paris, L'Harmattan, 2013, pp. 274.

1 Projet collectif, Socialisations, identités et résistances des romancières du Maghreb est le résultat d'un long travail interdisciplinaire qui a uni les efforts des universités de Lyon, Oran, Sousse et Béni-Mellal. À mi-chemin entre la sociologie et la littérature, cet essai frontalier analyse la production féminine maghrébine contemporaine en privilégiant une perspective sociologique orientée à la valorisation du document littéraire étudié: «sans réduire les textes [nord-africains] à des simples documents ou témoignages ethnographiques» (p. 14); les chercheurs ont essayé de récupérer la dimension émotionnelle, subjective et singulière qui anime la créativité littéraire féminine. Cet ouvrage comprend trois sections thématiques différentes: «Francophonies, identités et résistances» (pp. 32-115), «(En)jeux de genre, corps et sexualité» (pp. 116-187) et «Socialisations et trajectoires» (pp. 188-266).

Ancrées à un patrimoine culturel arabe et orientées vers un avenir occidental, les romancières évoquées dans la première partie de l'étude habitent un no-man's land atemporel où le passé et le futur se confondent, la langue maternelle et l'idiome du colonisateur précipitent dans un prisme linguistique qui renvoie une image hybride et 
déformée: la tunisienne Souâd Guellouz, les marocaines Nadia Chafiq et Bahaa Trabelsi et l'algérienne Assia Djebar récupèrent l'authenticité de leur voix «confisquée» (p. 102), se détachent du cliché de «la femme arabe» (p. 81) et enfin se dédient à une écriture de transhumance parce que «le choix définitif d'une seule langue ne peut qu'impliquer mort et stérilité» (p. 77), selon la définition de Najiba REGAÏEG.

En marche pour défendre l'autonomie idéologique et identitaire de la femme arabe, les romancières analysées dans la deuxième partie de l'étude célèbrent la créativité et le courage féminin. Fatima Bakhaï, Malika Mokeddem, Fériel Assima et Nina Bouraoui défendent ce que la chercheuse Faouzia BENDJELID définit «la résistance féminine» (p. 117). Les héroïnes littéraires évoquées dans La femme du Caïd (2003), L'Interdite (1993), Une femme à Alger. Chronique d'un désastre (1995) et Garçon manqué (2000) dépassent les frontières des interdits pour construire un itinéraire existentiel transgressif et pluriel: entre «excès et manque» (p. 139), elles sortent du Maghreb infecté par «le virus d'intolérance» (p. 142) pour s'exiler dans un horizon identitaire métisse où les opposés et les définitions s'annulent. Ni nord-africaine ni occidentale, l'héroïne littéraire évoquée dans la production maghrébine féminine est «l'autre des autres» (p. 151), selon la définition de Maha BEN ABDELADHIM: nomade, «accompagnée d'une forte charge émotionnelle subversive» (p. 151), elle combine «des nœuds d'oppressions multiples» (p. 152) et se réfugie dans un espace neutre qui alimente une écriture errante, «fragmentée, elliptique» (p. 156). «À la croisée des genres sexuels, interlangue et intergenre» (p. 170), l'héroïne littéraire contemporaine est une créature en devenir, porteuse d'un destin de diffraction et de rupture.

4 Sociologues et romancières, les auteures de la troisième section de l'essai réfléchissent sur le rôle que la famille exerce dans la transmissions des tabous sociaux: Fatma Zohra MEBTOUCHE NEDJAI et Souryana YASSINE, à travers le roman autobiographique Oumelkheir (1989) de l'algérienne Houaria Kadra-Hadjadji, réfléchissent sur les modalités éducatives qui déterminent l'apprentissage de l'interdit sexuel à l'intérieur de la cellule domestique; Abir KRÉFA analyse les variables sociologiques et culturelles qui favorisent le parcours d'affirmation littéraire de l'intellectuelle tunisienne contemporaine et enfin Isabelle CHARPENTIER présente les revendications identitaires de Sanaa Elaji, «scandaleuse transfuge de classe» (p. 231).

5 Socialisations, identités et résistances des romancières du Maghreb contribue à enrichir la réflexion sur le complexe univers féminin: les auteures des contributions analysées soulignent le courage et la détermination du sujet-femme méditerranéen parce que, comme disaient les féministes tunisiennes et égyptiennes en 2011, «la voix de la femme est révolution» (p. 5). Victimes d'une société hypocrite ou scandaleuses subversives, les maghrébines évoquées dans cet essai sont les exemples les plus précieux d'une communauté féminine qui défie les interdits et qui revendique l'unicité de son identité. «Au nord de tous les chemins» (p. 259), les transfuges du conformisme maghrébin récupèrent leur voix pour exprimer un je féminin enseveli dans le silence: «intrigue, confession, biographie et fiction» (p. 27), la femme maghrébine retrouve son pluralisme identitaire, dépasse la frontière des non-dits pour devenir «cette page blanche» (p. 29) où s'écrit l'avenir. 